\title{
POLYMER-CEMENTITIOUS COMPOSITES CONTAINING RECYCLED RUBBER PARTICLES
}

Carolina Coelho Martuscelli ${ }^{1}$, Pablo Resende Oliveira ${ }^{1}$, Túlio Hallak Panzera ${ }^{1 *}$, Maria Teresa Paulino Aguilar ${ }^{2}$, Carlos Thomas Garcia ${ }^{3}$

${ }^{1}$ Centre for Innovation and Technology in Composite Materials $-\mathrm{CIT}^{\mathrm{e}} \mathrm{C}$, Department of Mechanical Engineering, Federal University of São João del Rei - UFSJ, Praça Frei Orlando 170, Centro, 36307-352 Brazil. panzera@ufsj.edu.br (corresponding author)*

${ }^{2}$ Universidade Federal de Minas Gerais, Av. Presidente Antônio Carlos, 6627, Pampulha, 31270-901 Belo Horizonte, Minas Gerais, Brazil.

${ }^{3}$ LADICIM (Laboratory of Materials Science and Engineering), University of Cantabria. E.T.S. de Ingenieros de Caminos, Canales y Puertos, Av/Los Castros 44, 39005 Santander, Spain.

Abstract. The substantial disposal of non-biodegradable wastes is a major concern for the environment. One of the main disposed wastes is scrap tyres, whose production and disposal may lead to significant pollution of the soil and the air. This work investigates the effect of recycled rubber particles incorporation on the mechanical and physical properties of cementitious composites modified with epoxy polymer. A Design of Experiment (DoE) was conducted to identify the effect of the polymer inclusion (35 and 50wt.\%), rubber inclusion (10, 15 and 20wt.\%) and rubber particle size (coarse and fine particles) factors on the bulk density and compressive, tensile, and flexural strength and modulus responses. Epoxy polymer contributed to cement hydration, even without any water. Higher amount of coarse rubber particles led to reduced mechanical performance. In general, lower amounts of epoxy polymer and finer rubber aggregates provided superior strength and modulus. The use of epoxy polymer enhanced the adhesion between cement and rubber aggregates. This rubber polymercementitious composites achieved promising results, being a feasible alternative to reuse end-of-life rubber tyres into structural applications.

\section{Introduction}

The significant increase of solid waste disposal in nature is a major concern in many countries. One important example of discarded material is unusable tyres. Around 1 billion tyres end their service life per year and it is projected that 5 billion tyres are to be disposed by the year 2030 [1]. Although some countries, such as EU countries, have strict regulations about waste tyres destination, with a high recovery ratio of $96 \%$ [2], most discarded tyres have been sent to landfills without any treatment [1]. Tyre burning is the main destination for scrap tyres [2], however, this method is hazardous for environment, as burning areas are subjected to temperature rise and poisoned smoke is released during the combustion process. Since low quality components have been used to produce tyre rubber, waste tyres are economically unsuitable to be used as fuel [3]. 
The use of sustainable aggregates in construction industry has been proved to be a good solution as waste resources destination. Waste rubber particulates have been studied as viable aggregates for concrete production. Their incorporation in cement based materials has reduced carbon dioxide emissions, besides being economically viable [4] as an inexpensive resource with good energy absorption performance. Rubber particles have contributed to obtain light weight components, reducing overall density about $45 \%$, when coarse aggregates were used [5]. Past studies revealed that rubber aggregates provide slight reductions in compressive strength [6], flexural strength [7] and modulus of elasticity [8] of cementitious materials. This effect has been attributed to the weak rubber-cement adhesion, providing not only a faster crack propagation around rubber particles, but also agglomeration of rubber particulates in one face of concrete samples, leading to inhomogeneous composition [6]. On the other hand, higher energy absorption capacity of rubber particles changed concrete failure mode to ductile compared with normal brittle failure of ordinary concrete [9].

The use of chemical treatments, such as silane coupling agent and $\mathrm{NaOH}$ solution have contributed to increase overall rubber reinforced concrete strength by $15 \%$ [10]. Furthermore, the use of polymeric admixtures in cement products has led to increased mechanical properties due to enhanced bonding between cement hydrates and polymeric films [11]. Epoxy polymer is one of the main polymeric components in concrete and mortar compositions. It contributes to some advantages, such as high workability, ductile failure, increased flexural, compressive and tensile strength, reduced porosity and density of concrete samples [12]. Anagnostopoulos, Sapidis and Papastergiadis [13] have reported that $20 \%$ epoxy polymer was able to retard the hydration of Portland cement, leading to increments in compressive strength, tensile splitting strength and elastic modulus by $21 \%, 48 \%$, and $162 \%$, respectively. Although several studies have been conducted to assess the mechanical performance of epoxy polymer modified concrete, major efforts have been carried out to verify the influence of sustainable aggregates in such products. Shu and Zhang [14] have investigated epoxy polymer inclusions ( $40-60 \%$ ) into rubbered cementitious composites, achieving enhanced mechanical properties up to $275 \%$ under compressive loads.

In this context, in order to obtain a better understanding regards to the use of epoxy-rubber composites, a Design of Experiment (DoE) was conducted to assess statistically the influence of rubber particle size/amount, and epoxy incorporation on the mechanical, physical and morphological properties.

\section{Materials and Methods}

\subsection{Materials}

A thermoset polymer, consisted of epoxy resin (Renlam M type) and hardener (HY956 type) mixed at 5:1, respectively, was supplied by Huntsman (Brazil). The cementitious phase consisted of Portland Cement (ASTM III) was supplied by Holcim (Brazil). Rubber particles were sourced by a local remoulding company. Rubber 
particles were washed and classified by sieving process in particle size ranges of 10 20 US-Tyler (2-0.84mm) and 50-100 US-Tyler (0.297-0.149mm).

\subsection{Statistical Analysis}

A Design of Experiment (DoE) using a full factorial design was conducted to evaluate the significance of each experimental factor over the investigated responses. A full factorial design consists of investigating all combinations of experimental factors $(k)$ and their respective levels $(n)$, resulting in $n^{k}$ experimental conditions $[15,16]$. The statistical software Minitab 17 was used to manipulate the data.

Three experimental factors and their respective levels were evaluated as follows: epoxy polymer inclusion (35 and 50wt\%), rubber particle inclusion (10, 15 and 20wt\%) and size (10-20 and 50-100 US-Tyler). Holmes et al. [17] have recommended up to $20 \mathrm{wt} \%$ of rubber particle incorporation in cement based materials in order to avoid significant reductions in mechanical performance. The epoxy polymer amount levels were considered based on preliminary studies using similar raw materials [18, 19], involving particle packing optimization and optimum rheology of the system. A full factorial design $2^{2} 3^{1}$ was conducted, leading to 12 experimental conditions (Table 1 ). A reference condition (R1) with no rubber and polymer incorporation was prepared with a water-cement $(\mathrm{w} / \mathrm{c})$ ratio of 0.35 . Two blend compositions (R2 and R3) were also produced mixing epoxy polymer at different epoxy-cement ratios. The epoxy polymer in pristine condition (R4) was also evaluated. Table 2 shows the reference conditions. The investigated responses were bulk density and compressive, tensile, flexural strength / modulus.

TABLE 1. Full Factorial Design $2^{2} 3^{1}$

\begin{tabular}{cccc}
\hline $\begin{array}{c}\text { Experimental } \\
\text { Conditions }\end{array}$ & $\begin{array}{c}\text { Polymer } \\
\text { amount (\%) }\end{array}$ & $\begin{array}{c}\text { Rubber amount } \\
\text { (\%) }\end{array}$ & $\begin{array}{c}\text { Rubber particle } \\
\text { size (US-Tyler) }\end{array}$ \\
\hline \hline C1 & 50 & 10 & $10-20$ \\
\hline C2 & 50 & 10 & $50-100$ \\
\hline C3 & 50 & 15 & $10-20$ \\
\hline C4 & 50 & 15 & $50-100$ \\
\hline C5 & 50 & 20 & $10-20$ \\
\hline C6 & 50 & 20 & $50-100$ \\
\hline C7 & 35 & 10 & $10-20$ \\
\hline C8 & 35 & 10 & $50-100$ \\
\hline C9 & 35 & 15 & $10-20$ \\
\hline C10 & 35 & 15 & $50-100$ \\
\hline C11 & 35 & 20 & $10-20$ \\
\hline C12 & 35 & 20 & $50-100$ \\
\hline
\end{tabular}

TABLE 2. Reference conditions

\section{References}

Factors 


\begin{tabular}{cccc}
\hline & $\begin{array}{c}\text { Cement amount } \\
(\%)\end{array}$ & $\begin{array}{c}\text { Epoxy polymer } \\
\text { amount (\%) }\end{array}$ & $\begin{array}{c}\text { Water Cement } \\
\text { Ratio }\end{array}$ \\
\hline $\boldsymbol{R} 1$ & 100 & 0 & 0.35 \\
\hline $\boldsymbol{R} 2$ & 50 & 50 & 0 \\
\hline $\boldsymbol{R 3}$ & 65 & 35 & 0 \\
\hline $\boldsymbol{R 4}$ & 0 & 100 & 0 \\
\hline
\end{tabular}

\subsection{Experimental Procedure}

Cylindrical, prismatic and dog-bone samples were produced by hand-mixing ( $\sim 5$ min.) the bi-component matrix (cementitious and polymeric matrices) and dispersive phase based on the experimental setup shown in Tables 1 and 2. The samples were produced by pouring the mixture into silicone moulds. Cylindrical samples were also used to evaluate bulk density according to BS EN 10545 [23]. Bulk density was determined by the ratio between the weight and volume of the dried sample for $24 \mathrm{~h}$ in oven at $60^{\circ} \mathrm{C}$. Five (5) samples per test and experimental conditions were produced per replicate. Two replicates were adopted in this experiment. Samples were tested after 28 days of curing time at room temperature. Compressive, tensile, and flexural tests were conducted in a Shimadzu AGX universal machine with a $100 \mathrm{kN}$ load capacity in accordance with ASTM D695 [20], ASTM D638 [21], and ASTM D790 [22] recommendations, respectively.

The morphology of rubber/epoxy composites was evaluated via SEM (Scanning Electronic Microscopy), using a Hitachi Microscope - TM 3000 with $15 \mathrm{kV}$ voltage. SEM images were used to identify defects and the quality of interface between phases. The hydration of Portland cement by epoxy polymer was assessed via XRD (X-Ray Powder Diffraction), using an X-Ray Diffractor Shimadzu XRD 6000.

\section{Results and Discussions}

The mechanical and physical results obtained for the reference conditions are presented in Table 3. The limiting values were reached by the samples consisted of ordinary Portland cement paste (R1) and epoxy polymer in pristine condition (R4). With respect to R2 and R3 blends, higher compressive strength was achieved when $35 \mathrm{wt} \%$ of epoxy polymer was used (R3). An opposite behaviour was found for tensile and flexural strength, in which increased epoxy polymer $(50 \%)$ was more favourable compared with cement paste (R1) or cement with $35 \mathrm{wt} \%$ epoxy polymer (R3). The epoxy polymer in pristine condition achieved maximum compressive, tensile and flexural strengths. The elastic moduli under compressive, tensile and flexural loads presented similar trends, with highest values when $50 \mathrm{wt} \%$ cement was incorporated (R3), being attributed to the higher stiffness of Portland cement compared with epoxy polymer. The presence of polymeric phase provides additional influence on failure mode. Polymer-cementitious samples (R2-R3) revealed increased tenacity besides did 
not present brittle failure as cementitious samples (R1). R2 and R4 samples achieved higher deformations under compressive loads, as shown in Figure 2.

TABLE 3. Physical and mechanical properties mean values and standard deviations (in brackets) for the reference conditions

\begin{tabular}{cccccccc}
\hline & $\begin{array}{c}\boldsymbol{\sigma}_{\mathbf{c}} \\
(\mathbf{M P a})\end{array}$ & $\begin{array}{c}\mathbf{E}_{\mathbf{c}} \\
(\mathbf{G P a})\end{array}$ & $\begin{array}{c}\boldsymbol{\sigma}_{\mathrm{t}} \\
(\mathbf{M P a})\end{array}$ & $\begin{array}{c}\mathbf{E}_{\mathrm{t}} \\
(\mathbf{G P a})\end{array}$ & $\begin{array}{c}\boldsymbol{\sigma}_{\mathbf{f}} \\
(\mathbf{M P a})\end{array}$ & $\begin{array}{c}\mathbf{E}_{\mathbf{f}} \\
(\mathbf{G P a})\end{array}$ & $\begin{array}{c}\mathbf{\rho} \\
\left(\mathbf{g} / \mathbf{c m}^{\mathbf{3}}\right)\end{array}$ \\
\hline \hline \multirow{2}{*}{ R1 } & 53.12 & 47.83 & 1.57 & 11.60 & 9.71 & 10.92 & 1.94 \\
& $(2.22)$ & $(4.24)$ & $(0.15)$ & $(1.14)$ & $(1.06)$ & $(1.08)$ & $(0.03)$ \\
\hline \multirow{2}{*}{ R2 } & 70.05 & 27.47 & 19.81 & 6.13 & 41.00 & 5.31 & 1.56 \\
& $(2.83)$ & $(1.37)$ & $(1.79)$ & $(0.57)$ & $(3.49)$ & $(0.44)$ & $(0.03)$ \\
\hline \multirow{2}{*}{ R3 } & 81.37 & 37.95 & 12.21 & 9.56 & 35.90 & 6.61 & 1.79 \\
& $(1.79)$ & $(1.41)$ & $(0.83)$ & $(0.88)$ & $(3.19)$ & $(0.64)$ & $(0.02)$ \\
\hline \multirow{2}{*}{ R4 } & 91.92 & 19.31 & 40.10 & 1.83 & 75.96 & 2.83 & 1.16 \\
& $(2.72)$ & $(1.265)$ & $(2.07)$ & $(0.14)$ & $(4.25)$ & $(0.16)$ & $(0.02)$ \\
\hline
\end{tabular}

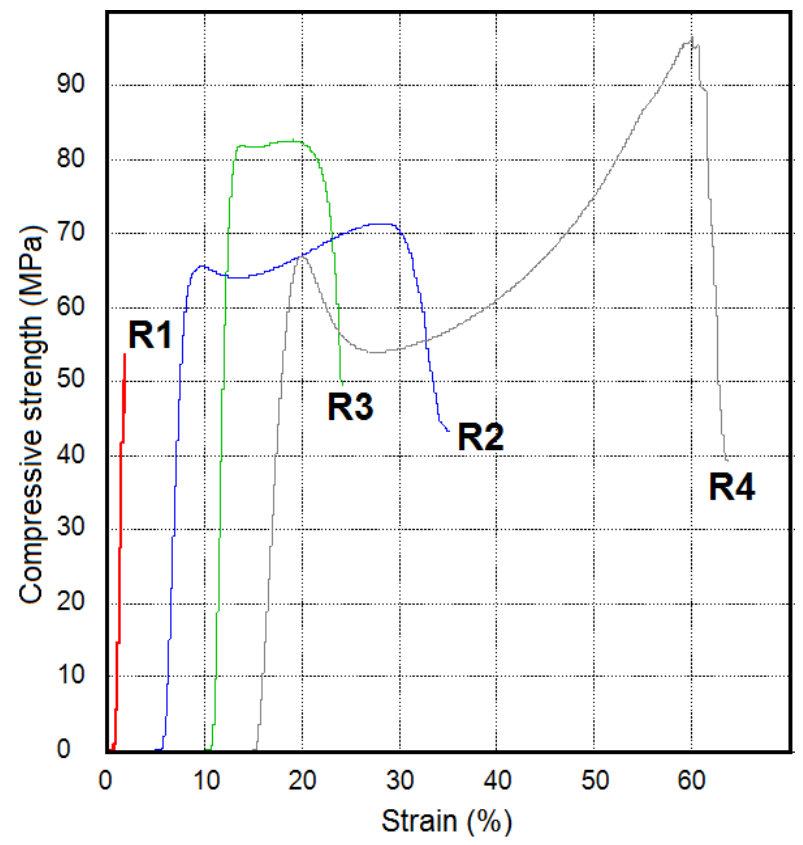

FIGURE 2. Stress vs. deformation plot obtained via compressive test for reference conditions.

Figure 3 shows XRD results for References 1 to 3 . The detected $2 \theta$ angles shown in Figure 3 are correspondent to hydrated cement products, including portlandite $\left(\mathrm{Ca}(\mathrm{OH})_{2}\right)$ and hydrated silica calcium $(\mathrm{CSH})$. XRD analysis evidenced cement hydration via water cement ratio in Reference 1 (Figure 3c) and epoxy polymer inclusion in References 2 (Figure 3a) and 3 (Figure 3b). Some peaks were only found for Reference 1, which indicate higher hydration by the presence of water. 


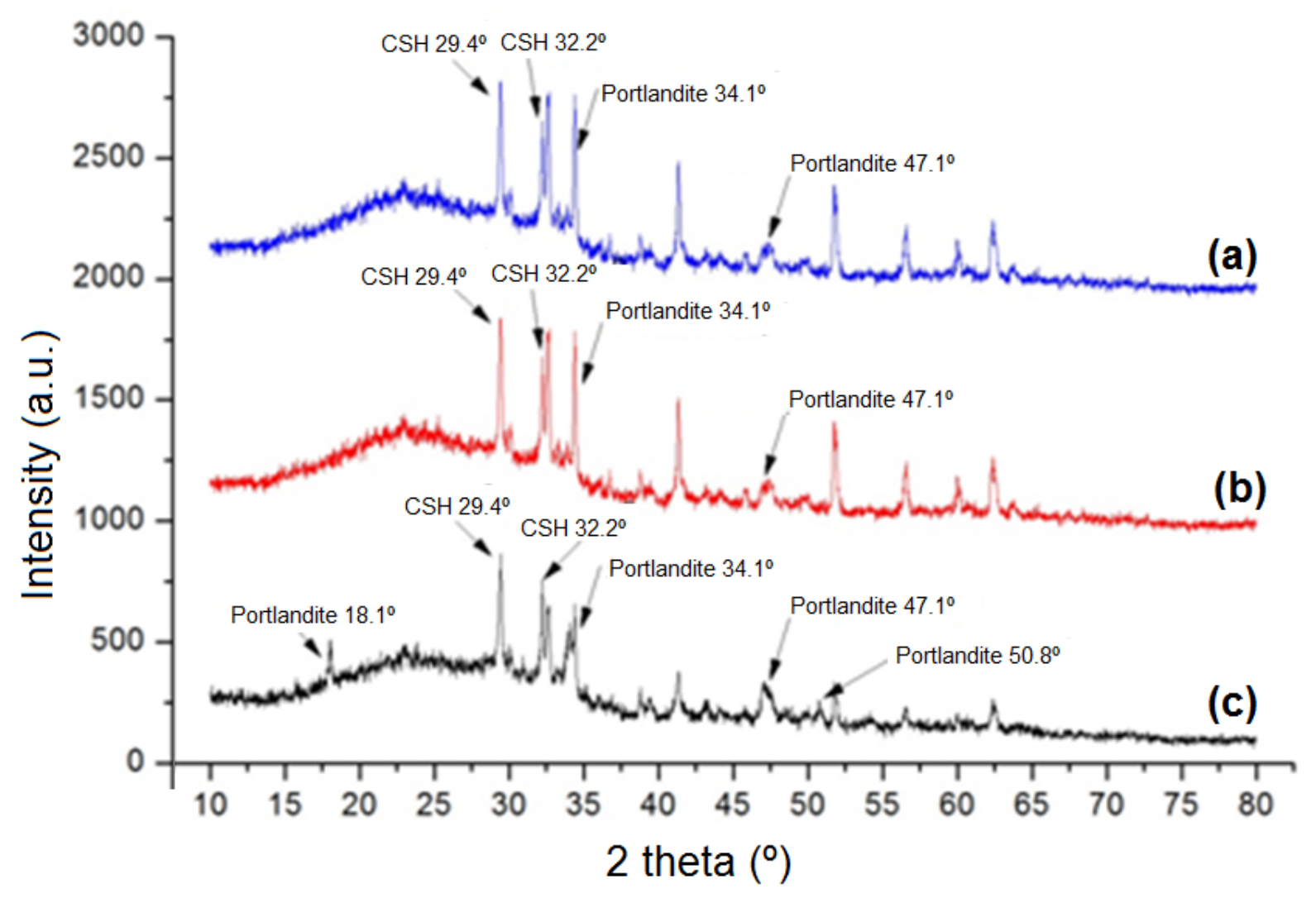

FIGURE 3. XRD analysis for epoxy-cement blends R2 (a) and R3 (b); and cement paste (c).

The results for mechanical and physical tests for experimental conditions are presented in Table 4. The statistical analysis was conducted via Analysis of Variance (ANOVA). The P-Value indicates which of the effects are significant in affecting the evaluated responses. When a P-Value for a factor or for the interaction of factors is lower than 0.05 , this factor or interaction have significant influence on the evaluated response within a $95 \%$ confidence interval. A main factor can only be considered individually when an interaction of two or more factors is not statistically significant. When an interaction of factors is significant, it represents a high order effect and those factors must be mutually considered using an interaction plot $[15,16]$. The P-Values for main effects and interactions for each mechanical and physical response are shown in Table 5. $R^{2}$-adjusted evidences the predictability of statistical model for new observations from obtained data. Anderson Darling test assesses the normality of tested data. Higher percentages for $\mathrm{R}^{2}$-ajdusted implies a model with good data adjustment. As can be seen in Table 4, all $R^{2}$-adjusted values are above $95 \%$, which indicate an excellent adjustment of the model. P-Values above 0.05 in AndersonDarling test indicate that investigated data follow normal distribution and validate ANOVA conclusions.

TABLE 4. Mean data considering replicate 1 and 2. 


\begin{tabular}{|c|c|c|c|c|c|c|c|c|c|c|c|c|c|c|}
\hline & \multicolumn{2}{|c|}{$\sigma_{c}(\mathrm{MPa})$} & \multicolumn{2}{|c|}{$E_{c}(G P a)$} & \multicolumn{2}{|c|}{$\sigma_{t}(\mathrm{MPa})$} & \multicolumn{2}{|c|}{$E_{t}(G P a)$} & \multicolumn{2}{|c|}{$\sigma_{\mathrm{f}}(\mathrm{MPa})$} & \multicolumn{2}{|c|}{$E_{f}(G P a)$} & \multicolumn{2}{|c|}{$\rho\left(\mathrm{g} / \mathrm{cm}^{3}\right)$} \\
\hline & Mean & SD & Mean & SD & Mean & SD & Mean & SD & Mean & SD & Mean & SD & Mean & SD \\
\hline C1 & 41.21 & 2.94 & 21.45 & 0.88 & 13.48 & 1.10 & 4.05 & 0.44 & 24.54 & 2.02 & 4.14 & 0.31 & 1.49 & 0.03 \\
\hline $\mathrm{C} 2$ & 45.32 & 2.54 & 21.90 & 1.21 & 15.93 & 1.03 & 3.88 & 0.33 & 24.97 & 1.79 & 5.40 & 0.46 & 1.50 & 0.03 \\
\hline C3 & 36.93 & 1.20 & 18.77 & 1.25 & 10.00 & 0.87 & 3.20 & 0.46 & 19.52 & 1.64 & 3.78 & 0.16 & 1.48 & 0.02 \\
\hline C4 & 42.98 & 0.74 & 21.86 & 2.00 & 16.24 & 1.22 & 5.58 & 0.32 & 29.67 & 2.77 & 4.92 & 0.29 & 1.47 & 0.01 \\
\hline C5 & 34.28 & 1.27 & 19.91 & 1.49 & 9.62 & 0.88 & 4.68 & 0.44 & 21.91 & 1.59 & 2.38 & 0.20 & 1.44 & 0.01 \\
\hline $\mathrm{C} 6$ & 40.47 & 1.23 & 19.12 & 1.34 & 12.68 & 0.57 & 4.19 & 0.31 & 26.07 & 2.05 & 3.96 & 0.34 & 1.46 & 0.01 \\
\hline $\mathrm{C} 7$ & 50.78 & 1.56 & 26.98 & 1.37 & 11.49 & 1.30 & 3.94 & 0.35 & 26.86 & 1.99 & 3.98 & 0.36 & 1.73 & 0.01 \\
\hline C8 & 60.75 & 1.27 & 30.42 & 1.39 & 15.73 & 1.33 & 4.08 & 0.42 & 31.80 & 2.96 & 6.04 & 0.60 & 1.76 & 0.01 \\
\hline C9 & 39.70 & 1.32 & 22.64 & 1.02 & 9.17 & 0.64 & 3.28 & 0.60 & 22.98 & 1.95 & 4.57 & 0.35 & 1.67 & 0.01 \\
\hline C10 & 46.31 & 2.85 & 24.94 & 1.98 & 14.68 & 0.88 & 5.60 & 0.40 & 23.65 & 2.04 & 5.26 & 0.43 & 1.71 & 0.04 \\
\hline C11 & 25.50 & 2.45 & 17.70 & 1.47 & 9.02 & 0.71 & 4.80 & 0.52 & 19.71 & 1.66 & 4.18 & 0.25 & 1.63 & 0.06 \\
\hline C12 & 38.80 & 3.24 & 22.89 & 1.73 & 12.95 & 1.00 & 4.27 & 0.24 & 20.00 & 1.24 & 6.05 & 0.28 & 1.65 & 0.04 \\
\hline
\end{tabular}

TABLE 5. Analysis of variance (P-Values $\leq 0.05)$

\begin{tabular}{|c|c|c|c|c|c|c|c|c|}
\hline & Factors & $\sigma_{c}(\mathrm{MPa})$ & $E_{c}(G P a)$ & $\sigma_{t}(\mathrm{MPa})$ & $E_{t}(G P a)$ & $\sigma_{\mathrm{f}}(\mathrm{MPa})$ & $E_{f}(G P a)$ & $\begin{array}{c}\rho \\
\left(\mathrm{g} / \mathrm{cm}^{3}\right)\end{array}$ \\
\hline \multirow{3}{*}{$\frac{.5}{\Sigma \frac{\pi}{\pi}}$} & $\begin{array}{l}\text { Epoxy } \\
\text { inclusion } \\
\text { (EI) }\end{array}$ & $\underline{0.000}$ & $\underline{0.000}$ & $\underline{0.000}$ & $\underline{0.000}$ & 0.377 & $\underline{0.000}$ & $\underline{0.000}$ \\
\hline & $\begin{array}{l}\text { Rubber } \\
\text { inclusion } \\
\text { (RI) }\end{array}$ & $\underline{0.000}$ & $\underline{0.000}$ & $\underline{0.000}$ & $\underline{0.000}$ & $\underline{0.000}$ & $\underline{0.000}$ & $\underline{0.000}$ \\
\hline & $\begin{array}{l}\text { Rubber } \\
\text { particle } \\
\text { size (RS) }\end{array}$ & $\underline{0.000}$ & $\underline{0.000}$ & $\underline{0.000}$ & $\underline{0.000}$ & $\underline{0.000}$ & $\underline{0.000}$ & $\underline{0.005}$ \\
\hline \multirow{6}{*}{ 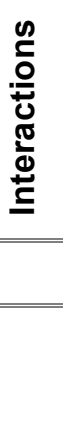 } & $\mathrm{El}^{*} \mathrm{RI}$ & $\underline{0.000}$ & $\underline{0.000}$ & $\underline{0.026}$ & $\underline{0.001}$ & $\underline{0.000}$ & $\underline{0.000}$ & $\underline{0.000}$ \\
\hline & EI*RS & $\underline{0.000}$ & $\underline{0.000}$ & $\underline{0.046}$ & 0.297 & $\underline{0.000}$ & 0.144 & 0.030 \\
\hline & $\mathrm{RA}^{*} \mathrm{RS}$ & $\underline{0.006}$ & 0.327 & $\underline{0.000}$ & 0.314 & $\underline{0.002}$ & $\underline{0.001}$ & 0.278 \\
\hline & $\mathrm{El}^{*} \mathrm{R}{ }^{*} \mathrm{RS}$ & $\underline{0.008}$ & $\underline{0.000}$ & $\underline{0.014}$ & $\underline{0.002}$ & $\underline{0.000}$ & $\underline{0.010}$ & 0.435 \\
\hline & $\mathrm{R}^{2}(\operatorname{adj})$ & $98.89 \%$ & $98.14 \%$ & $98.19 \%$ & $95.86 \%$ & $96.24 \%$ & $97.44 \%$ & $99.04 \%$ \\
\hline & $\begin{array}{l}\text { Anderson } \\
\text { Darling } \\
\text { Test }\end{array}$ & 0.531 & 0.086 & 0.610 & 0.215 & 0.281 & 0.110 & 0.537 \\
\hline
\end{tabular}

\subsection{COMPRESSIVE STRENGTH AND MODULUS}

Compressive strength data varied from 24.17 MPa to $61.12 \mathrm{MPa}$. The incorporation of rubber particles led to reduced compressive strength from $25 \%$ up to $70 \%$ in comparison with their respective polymer-cementitious sample-references for all tested conditions (see Table 4). A third order interaction effect was significant on strength showing a P-value (0.008) lower than 0.05 (Table 5). Figure 4 shows the interaction 
effect plot for mean compressive strength. Smaller particle sizes led to higher strength, mainly when the composites are fabricated with lower amount of rubber (see Figure $4 a$ ) and epoxy polymer (see Figure 4b). Smaller size aggregates have contributed to higher particle packing and reduced sample porosity as reported by Azevedo et al. [6]. Not only reduced density of rubber particles $\left(2.83 \mathrm{~g} / \mathrm{cm}^{3}\right)$ compared to cement particles $\left(3.12 \mathrm{~g} / \mathrm{cm}^{3}\right)$ [18], but also the lower rubber/cement bonding [24] have contributed to decreased strength of rubber/polymer-cementitious composites under compressive load. Compressive strength was significantly reduced by $42.3 \%$ when rubber particles were combined with epoxy polymer at lower amount (35\%), as demonstrated in Figure 4c. Although the lower level of polymer amount (35\%) is more sensitive to rubber particle inclusions, this level achieved the highest compressive strength when $10 \%$ of rubber is considered (Figure 4c).

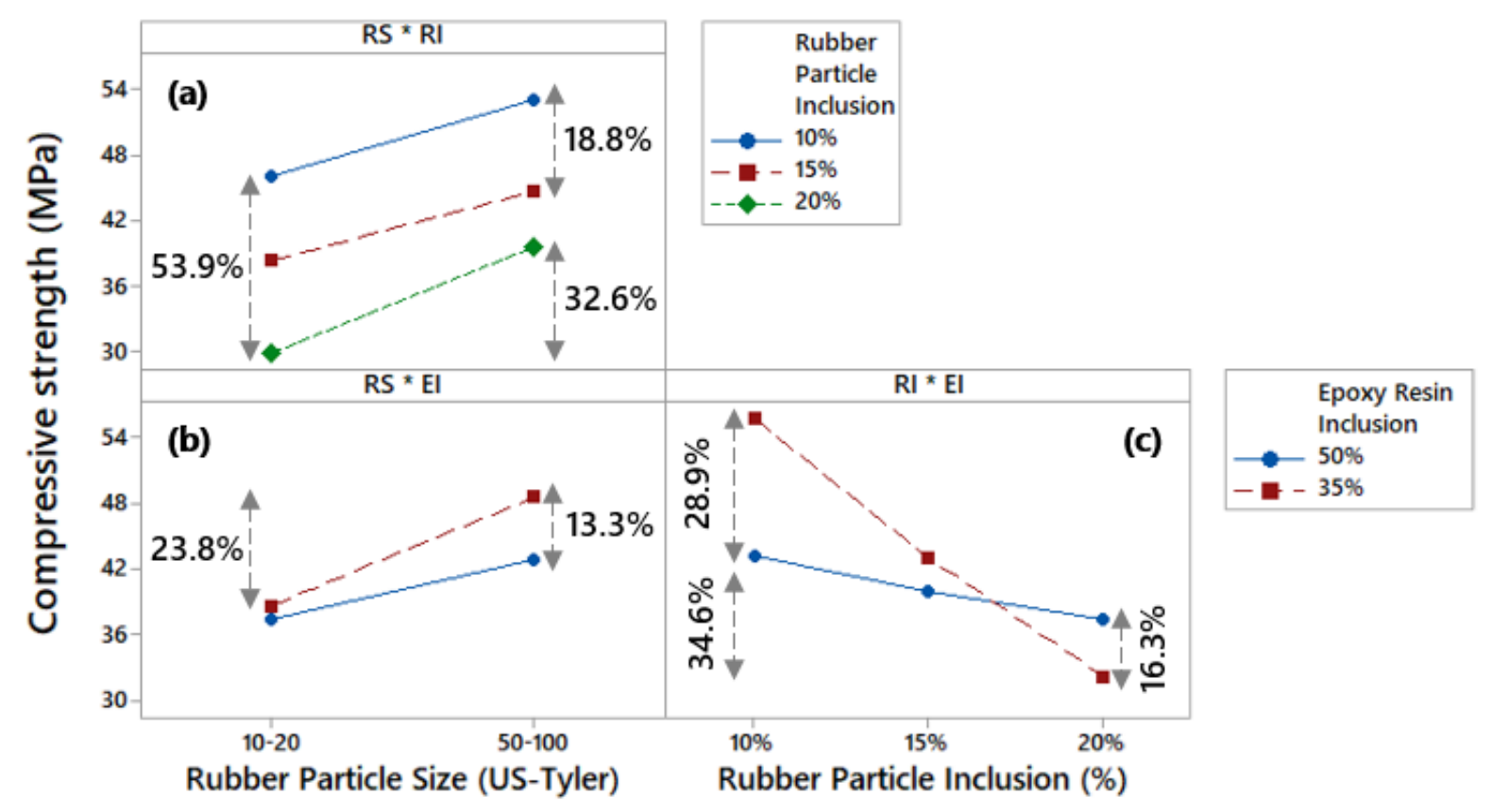

FIGURE 4. Third order interaction effect plot for mean compressive strength.

Compressive modulus data varied from $16.8 \mathrm{GPa}$ to $30.9 \mathrm{GPa}$. In general, compressive strength and modulus have achieved analogous behaviour in cementitious samples, although the degree of changes for elastic modulus has been progressively lower [25]. Significant reductions in mean compressive modulus compared to References 2 and $3(32.7 \%$ and $51.8 \%$, respectively) were found as previously discussed. Figure 5 shows the interaction effect plots for mean compressive modulus. Lower amount of fine rubber particles with epoxy polymer led to higher compressive moduli. 


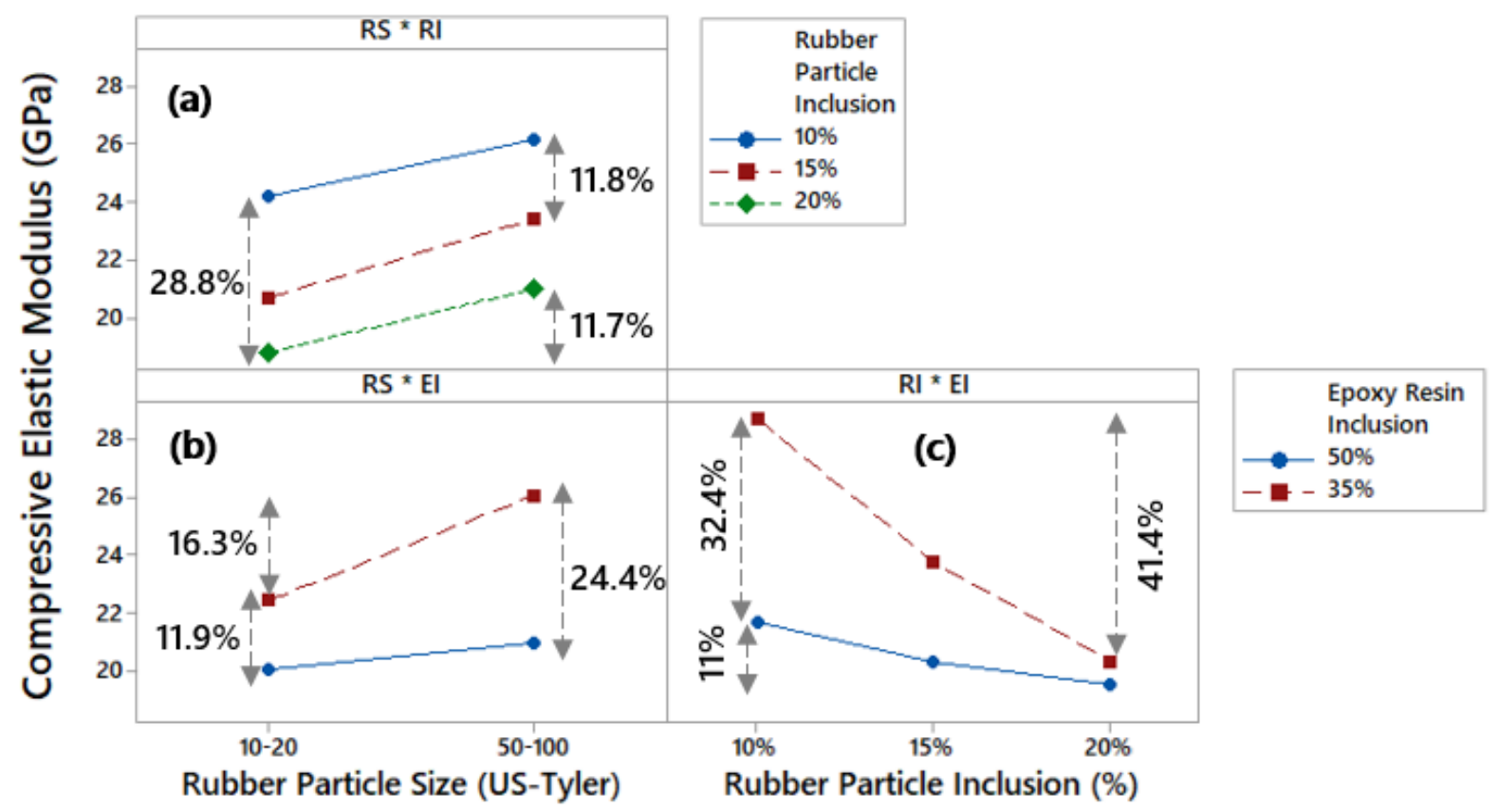

FIGURE 5. Third order interaction effect plot for mean compressive modulus.

\subsection{TENSILE STRENGTH AND MODULUS}

Tensile strength data varied from 8.81 to $16.32 \mathrm{MPa}$. A third order interaction effect was significant achieving P-value lower than 0.05 . In contrast to the compressive behaviour, higher tensile strength was achieved when increased amount of epoxy polymer was considered, as shown in Figures $6 \mathrm{~b}$ and $6 \mathrm{c}$. This behaviour agrees with the results obtained for tensile tests in References 2 and 3 , in which $50 \%$ resin content (R2) led to $62 \%$ increase in tensile strength compared with $35 \%$ epoxy incorporation (R3). Coarse aggregate and higher rubber particle inclusions contributed to significant reductions (31.5 and $25.7 \%$ ) in tensile strength. Similar strength values were obtained when 10 or $15 \%$ of fine rubber particles were used (Figure 6.a). Composites made with $35 \%$ epoxy polymer achieved higher strength (nearly at $25 \%$ ) when compared to R3, which was fabricated with fine rubber particles at $10 \%$ level. This behaviour can be attributed to an enhanced particle packing system and reduced porosity. Tensile strength data were lower than R3 baseline only when coarse aggregate was used. 


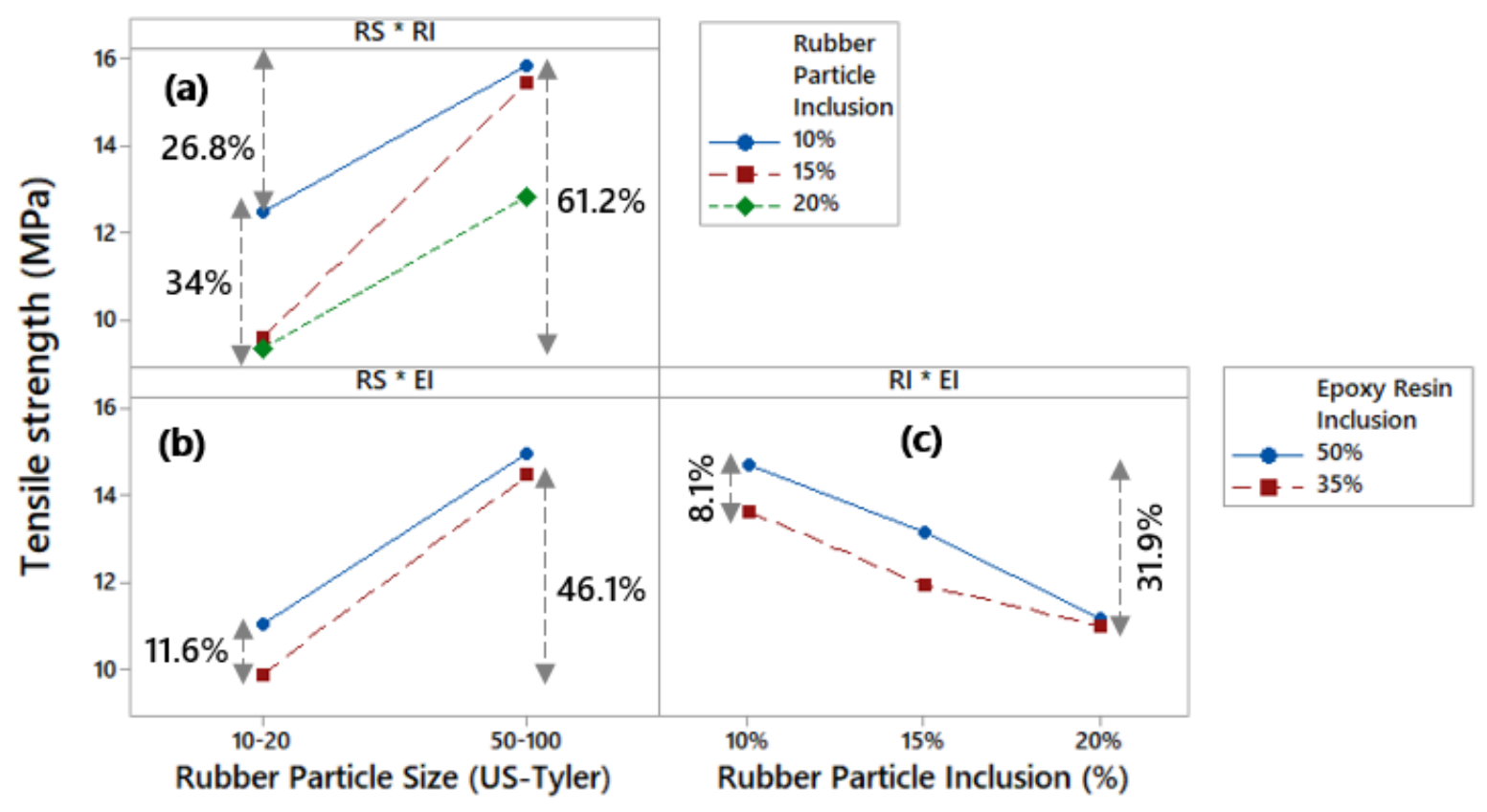

FIGURE 6. Third order interaction effect plot for mean tensile strength.

Tensile moduli varied from 2.73 to $5.73 \mathrm{GPa}$. The reference conditions achieved superior strength when compared to the experimental treatments. A third order interaction significantly affected this response (see Table 4). Higher elastic modulus was identified for $35 \%$ epoxy polymer inclusion (Figures $7 \mathrm{~b}$ and $7 \mathrm{c}$ ) and fine rubber particles (Figures $7 \mathrm{a}$ and $7 \mathrm{~b}$ ). The change from 10 to $15 \%$ rubber amount did not affect the stiffness when $50 \%$ epoxy polymer was considered (Figure 7c). Reductions in tensile modulus were identified when $20 \%$ coarse rubber aggregate were used, agreeing with tensile strength results. Although cementitious samples achieved lower tensile performance than polymeric ones, the presence of cement particles led to enhanced composite stiffness, contributing to higher tensile modulus.

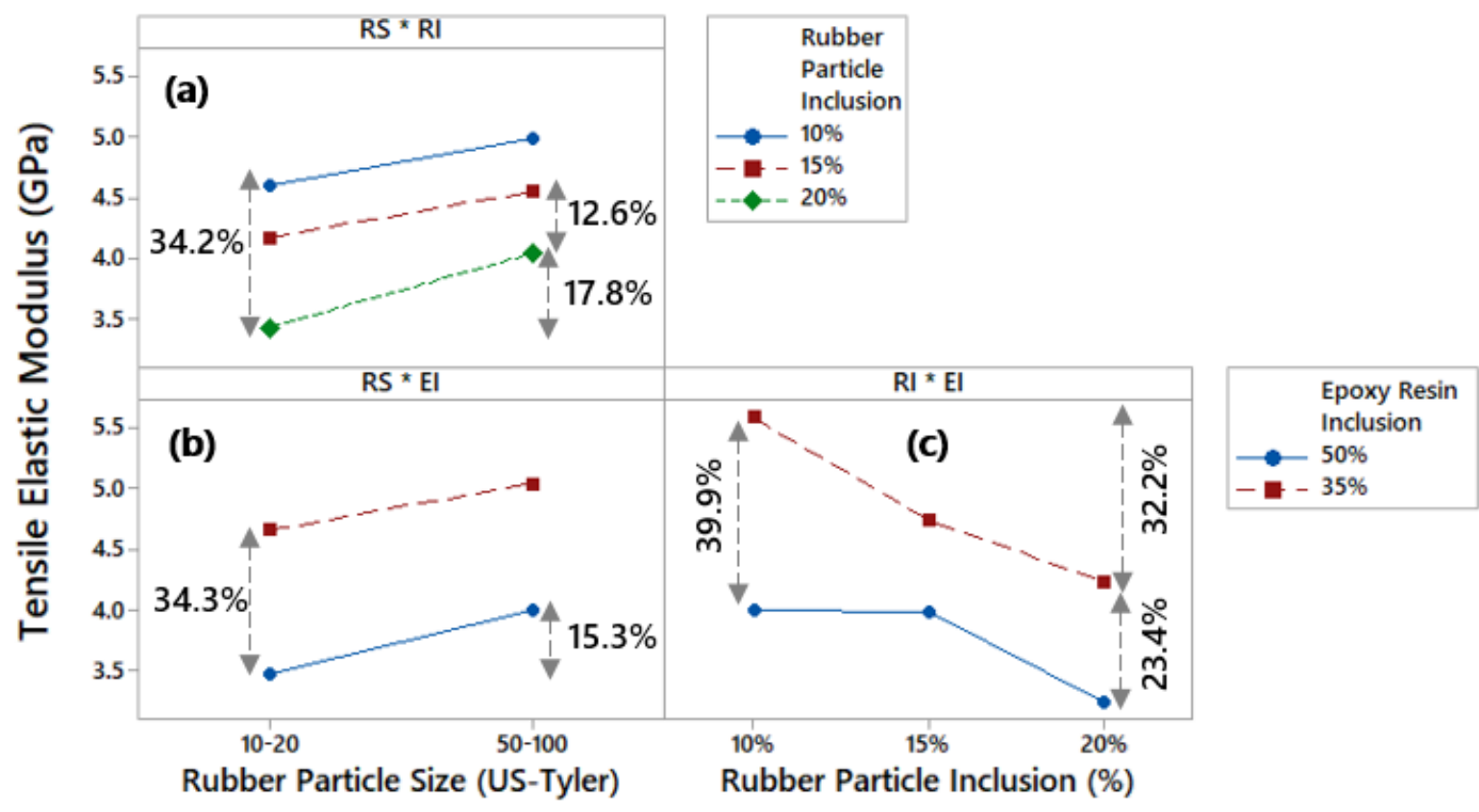

FIGURE 7. Third order interaction effect plot for mean tensile modulus. 


\subsection{FLEXURAL STRENGTH AND MODULUS}

Flexural strength data varied from 19.02 to $32.26 \mathrm{MPa}$. The third order interaction effect was significant with a P-value lower than 0.05 (Table 5). Highest flexural performance was achieved for composites made with $10 \%$ fine rubber fraction and higher cement levels (65\% cement/35\% epoxy polymer). In this case, the increase in flexural strength may be attributed to the superior mechanical behaviour promoted by the cementitious phase under compressive loads, which is present in flexural tests [26]. Coarse aggregate led to significant reduction in flexural strength for all levels of rubber and epoxy polymer (see Figures 8a and 8b), which agrees with past studies [7, 24]. Rubber particle amount and size provided different influences over the flexural strength, depending on the epoxy polymer fraction, according to Figures $8 \mathrm{~b}$ and $8 \mathrm{c}$. Rubber inclusions did not affect flexural strength when $50 \%$ epoxy polymer was considered, which can be attributed to a better bonding condition (Figure 8c). On the other hand, higher rubber amount contributed to reduce dramatically flexural strength at about $32.3 \%$, mainly when a smaller polymer amount was used (Figure 8c).

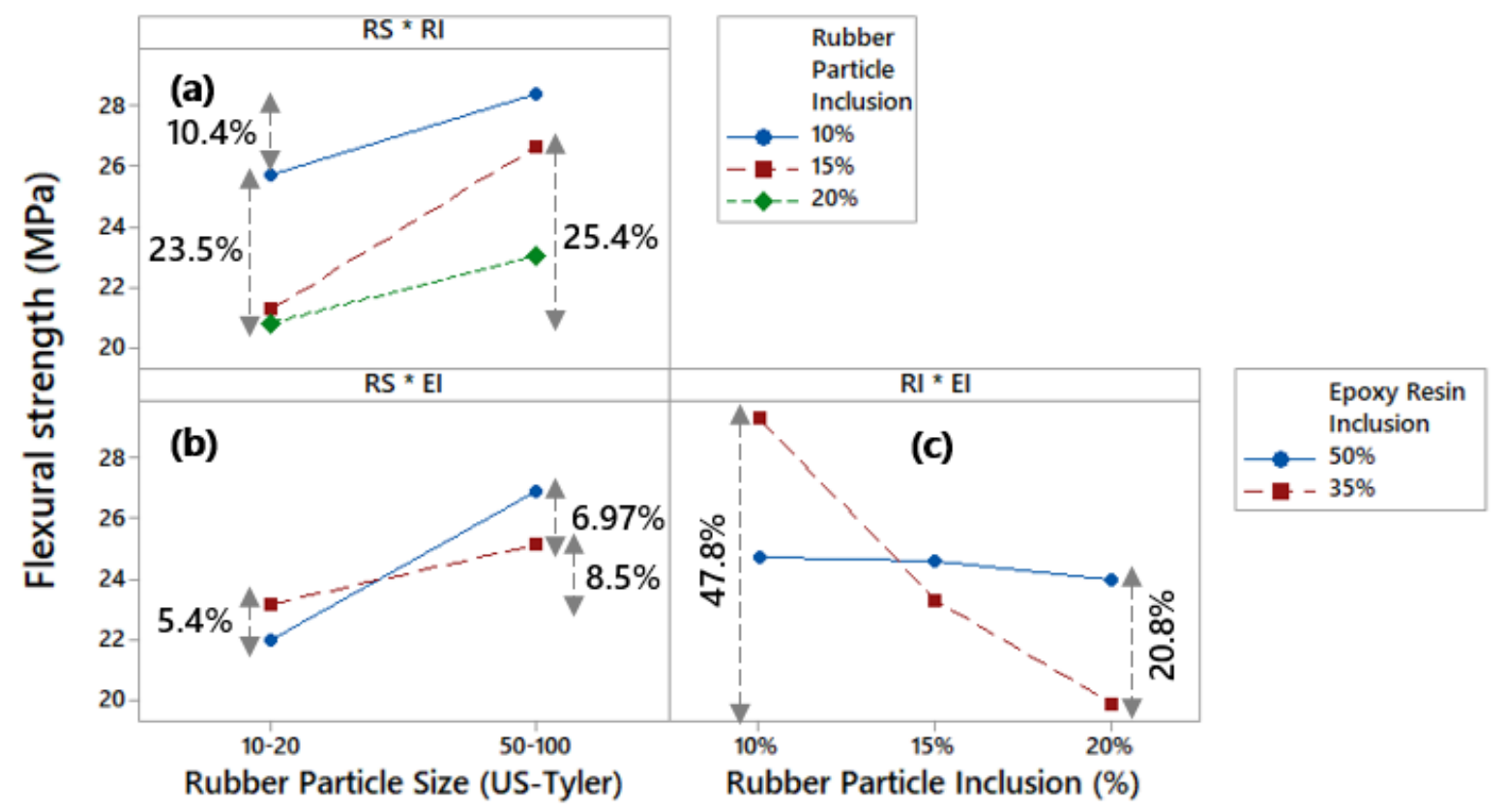

FIGURE 8. Interaction effect plot for mean flexural strength.

Flexural moduli ranged from 2.29 to $6.24 \mathrm{GPa}$. Figure 9 shows the third order interaction effect plot for mean flexural modulus. In general, flexural moduli presented significant reductions when larger amount of rubber particles was used (Figure 9a). However, higher modulus was achieved when $35 \%$ epoxy polymer was added (Figure $9 \mathrm{~b}$ and $9 \mathrm{c}$ ), as the cementitious phase contributes to enhance the stiffness. Flexural modulus increases at nearly $24 \%$ for both rubber particle size levels when larger amount of Portland cement is used (Figure 9b). Fine rubber particles led to higher stiffness (Figure 9a and 9b). An opposite behaviour was found for flexural modulus compared with flexural strength (Figure 8c) when the effect of polymer and rubber inclusions was evident (Figure 9c). The presence of a larger amount of Portland 
cement (35\% epoxy polymer level) can enhance the matrix phase stiffness leading to higher elastic modulus even when a larger amount of rubber $(20 \%)$ is considered (Figure 9c).

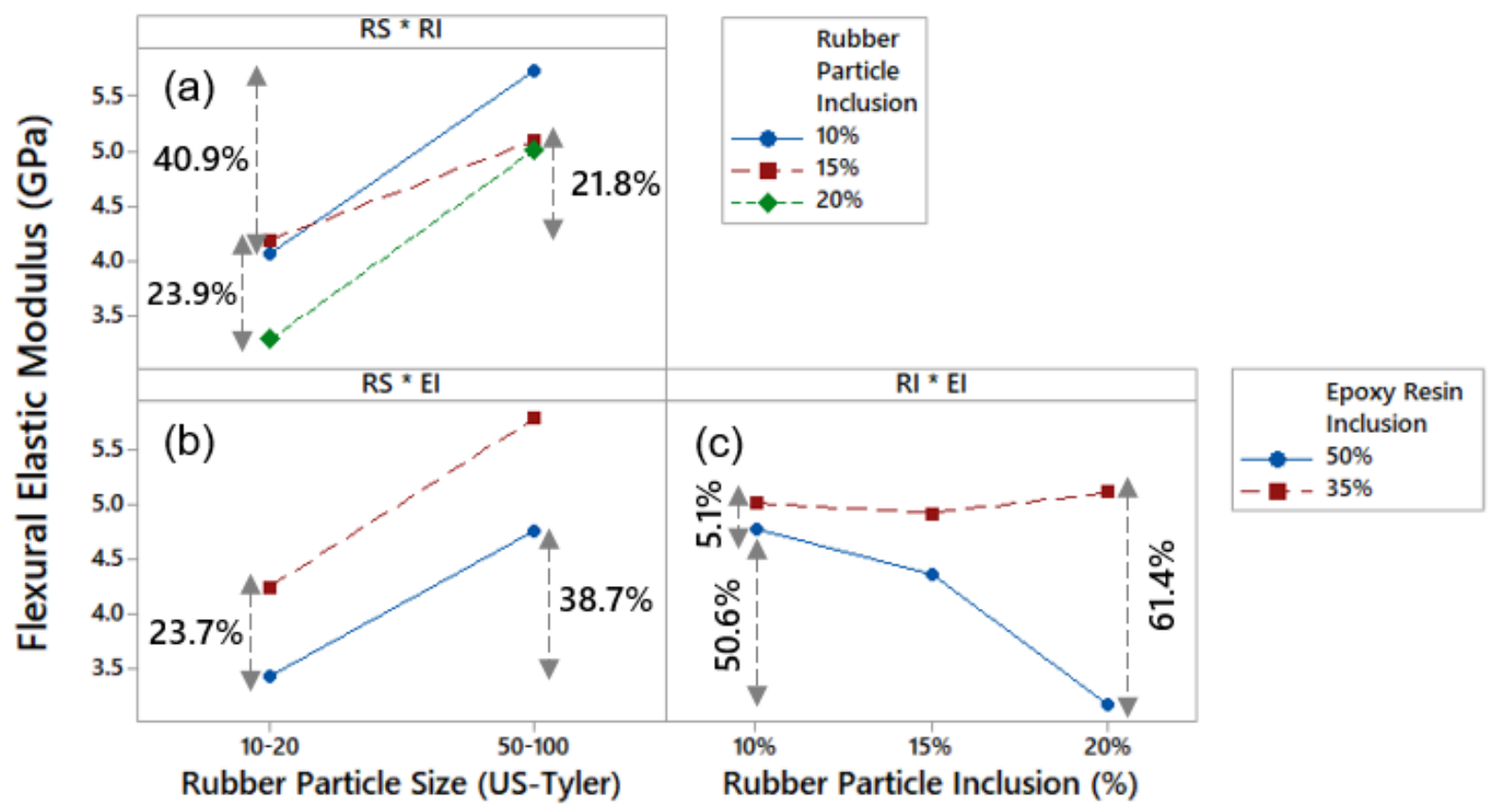

FIGURE 9. Interaction effect plot for mean flexural modulus.

\subsection{BULK DENSITY}

Table 4 shows that bulk density response presented two significant second order interaction effects (Figure 10) with P-Values lower than 0.05. Bulk density data ranged from 1.440 to $1.759 \mathrm{~g} / \mathrm{cm}^{3}$. The incorporation of rubber particles led to reduced bulk density for all experimental conditions compared with reference samples $[8,27]$. Figure $10 \mathrm{a}$ reveals the higher level of polymer inclusion (50\%) reduces bulk density nearly at $13 \%$, which is in agreement to the literature review [28]. Rubber particle size factor did not provide a substantial effect on bulk density; however, a slight reduction is noted when coarse particles are used. Higher rubber amounts provided further density reductions for both epoxy polymer levels (Figure 10b), since the aggregates exhibit lower density compared with the matrix phase. This reduction is more evidenced by the composites fabricated with larger amount of cement which means $35 \%$ epoxy polymer. 

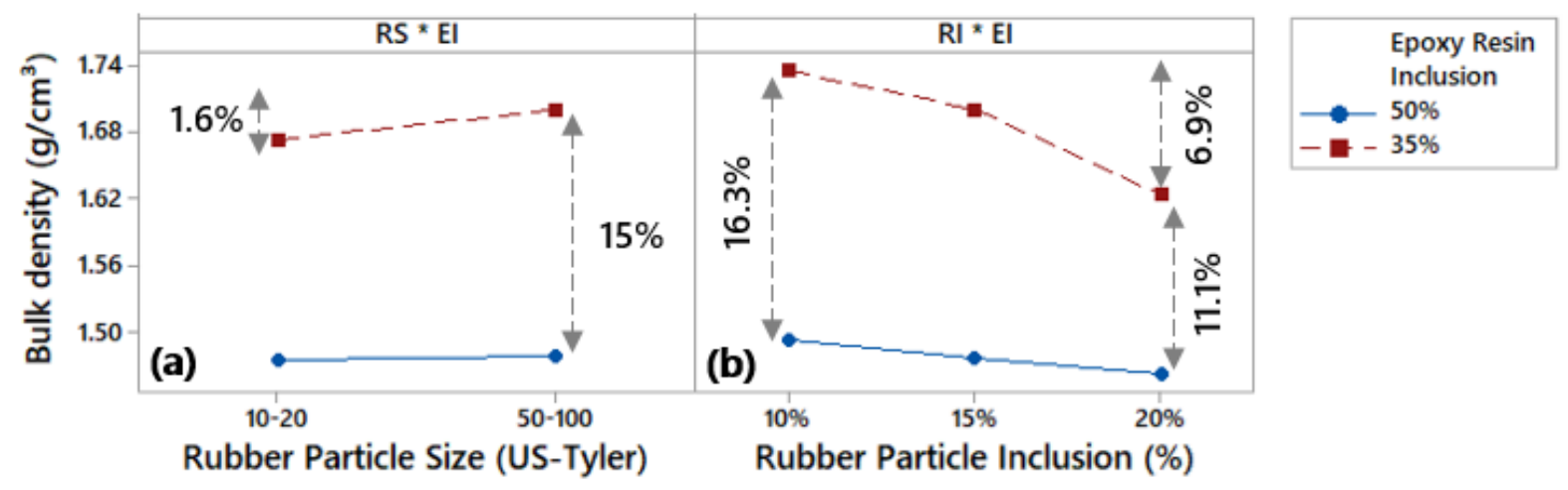

FIGURE 10. Second order interaction effect plots for the mean bulk density: (a) epoxy polymer and rubber particle inclusions and (b) epoxy polymer inclusion and rubber particle size

\subsection{MICROSTRUTURAL ANALYSIS}

Figure 11 shows SEM images for samples made with (a) 50\% epoxy polymer/10\% coarse rubber $-\mathrm{C} 1$, (b) $50 \%$ epoxy polymer $10 \%$ fine rubber particles $-\mathrm{C} 2$, (c) $35 \%$ epoxy polymer $/ 10 \%$ coarse rubber $-\mathrm{C} 7$, (d) $35 \%$ epoxy polymer $/ 10 \%$ fine rubber particles $-\mathrm{C} 8$, at $100 \times$ of magnification. Reduced mechanical performance achieved by composites made with coarse rubber particles (10-20 US-Tyler) can be explained due to their higher rubber volume fraction (Figure 11a and $\mathrm{c}$ ). The matrix phase containing epoxy polymer and Portland cement presents higher strength and stiffness when compared to the rubber particles. Consequently, composites fabricated with fine rubber particles (Figure 11b and d) led to larger amount of matrix phase which contributes to enhance their mechanical properties. A good matrix-rubber adhesion is verified for all conditions, as no pore was identified at the interface transition zone. Micropores, indicated by red arrows, were observed around the matrix phase for all conditions, which can be attributed to the entrapped air during the mixing process. Larger presence of white spots in Figures $11 \mathrm{c}$ and 11d evidences a higher concentration of Portland cement. 


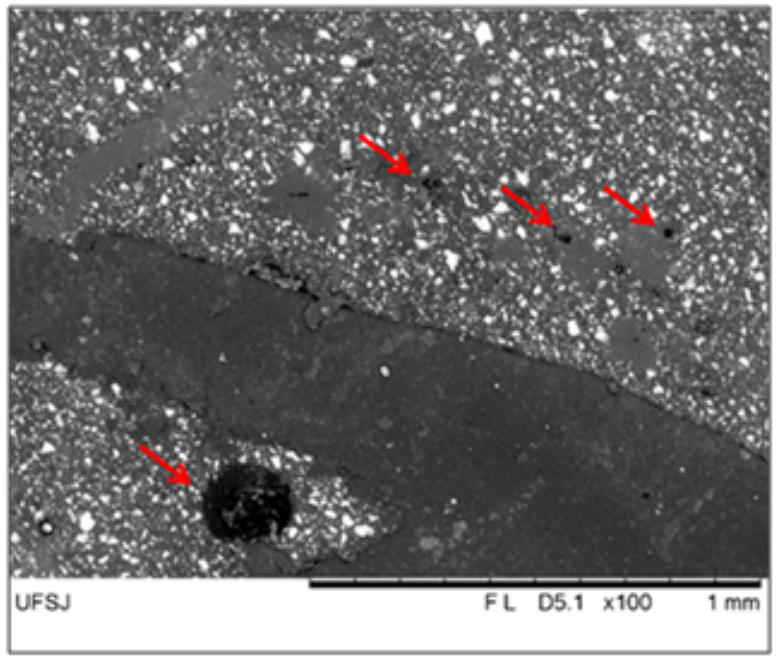

(a) $\mathrm{C1}$

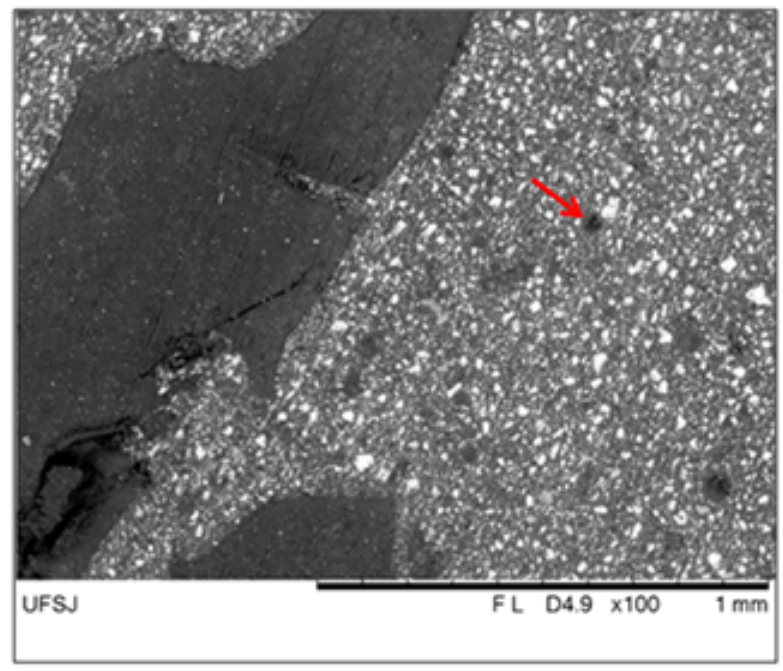

(c) $\mathrm{C7}$

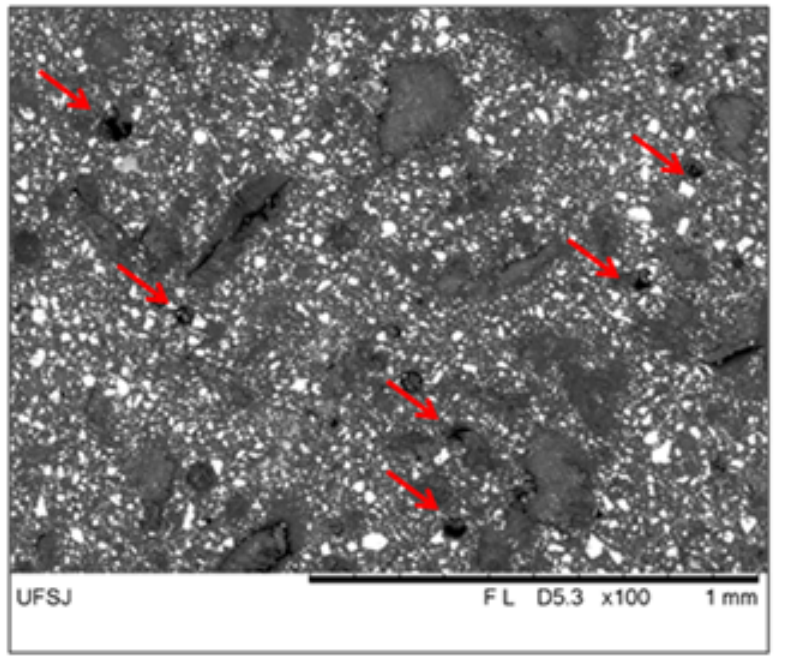

(b) $\mathrm{C2}$

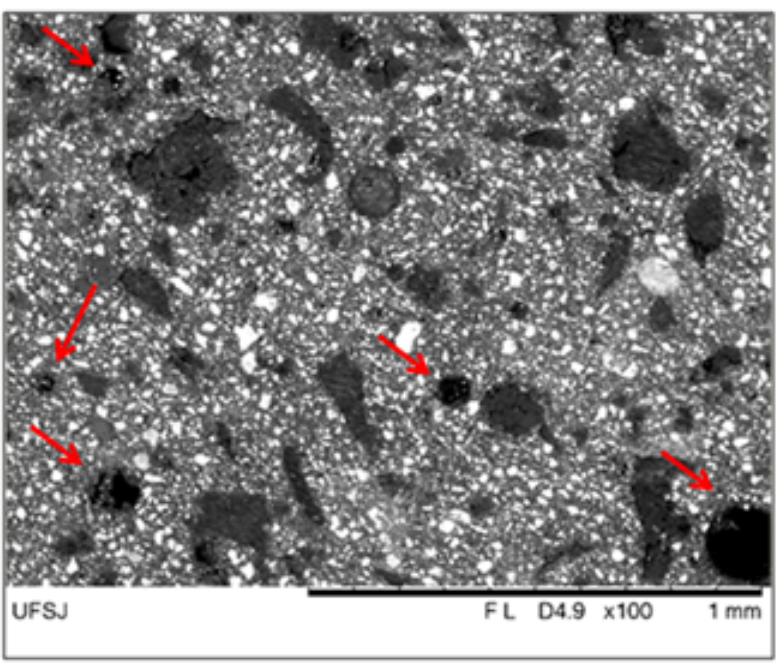

(d) $\mathrm{C} 8$

FIGURE 11. SEM images at 100× magnification for samples with (a) $50 \%$ epoxy resin/ $10 \%$ coarse rubber, (b) 50\% epoxy resin/10\% fine rubber particles, (c) $35 \%$ epoxy resin/ $10 \%$ coarse rubber, (d) $35 \%$ epoxy resin/ $10 \%$ fine rubber particles.

\section{CONCLUSIONS}

The incorporation of waste tyre rubber particles into polymer-cementitious composites was investigated. Epoxy polymer contributed to enhance mechanical strength under compressive, tensile and flexural loads. Flexural and tensile strength increased by $324 \%$ and $1122 \%$, respectively. In addition, X-Ray diffractometry analyses evidenced cement hydration provided by epoxy polymer even with no water content. Rubber particle inclusions promoted significant reductions in compressive and flexural strength/modulus. Composites made with 35\% epoxy polymer achieved a slight increase in tensile modulus when fine rubber particles were used. Composites constituted of $50 \%$ epoxy polymer and $10 \%$ fine rubber aggregates led to higher tensile strength values. In general, composites fabricated with $10 \%$ fine rubber aggregates 
and $35 \%$ epoxy polymer achieved superior mechanical performance, i.e. $60.75 \mathrm{MPa}$ and $30.42 \mathrm{GPa}$ in mean compressive strength and modulus, $15.73 \mathrm{MPa}$ and $4.08 \mathrm{GPa}$ in mean tensile strength and modulus, and $31.80 \mathrm{MPa}$ and $6.04 \mathrm{GPa}$ in mean flexural strength and modulus, respectively. In contrast, higher epoxy and coarse rubber amount contributed to reduce samples density. The incorporation of rubber provided reductions in mechanical properties compared to the pristine conditions, however, other characteristics such as damping factor, surface friction, low permeability, thermal and acoustic insulation might be enhanced, being the scope of future investigations. Finally, polymer-cementitious containing rubber particles proved to be a promising material for sustainable construction, in which moderate resistance and low weight are required.

\section{REFERENCES}

1. THOMAS, B. S., GUPTA, R. C. A comprehensive review on the applications of waste tyre rubber in cement concrete, Renewable and Sustainable Energy Reviews, 54 (2016), pp. 1323-1333.

2. BRAVO, M., DE BRITO, J. Concrete made with used tyre aggregate: durabilityrelated performance. J Clean Prod, 25 (2012), pp. 42-50

3. MOHAMMED, B.S., HOSSAIN, K.M.A., SWEE, J.T.E., WONG, G., ABDULLAHI, M. Properties of crumb rubber hollow concrete block. J Clean Prod, 23 (2012), pp. 5767.

4. AZEVEDO, F., PACHECO-TORGAL, F., JESUS, C., DE AGUIAR, J.B., CAMÕES, A.F. Properties and durability of HPC with tyre rubber wastes. Constr Build Mater, 34 (2012), pp. 186-191

5. PACHECO-TORGAL, F., DING, S. J. Y. Properties and durability of concrete containing polymeric wastes (tyre rubber and polyethylene terephthalate bottles): an overview. Constr Build Mater, 30 (2012), pp. 714-724.

6. AZEVEDO, F., PACHECO-TORGAL, F., JESUS, C., DE AGUIAR, J.B., CAMÕES, A.F. Properties and durability of HPC with tyre rubber wastes. Constr Build Mater, 34 (2012), pp. 186-191

7. SU, H., YANG, J., LING, T.C., GHATAORA, G.S., DIRAR, S. Properties of concrete prepared with waste tyre rubber particles of uniform and varying sizes. J Clean Prod (2014).

8. GESOĞLU, M., GÜNEYISI, E., KHOSHNAW, G., IPEK, S. Investigating properties of pervious concretes containing waste tyre rubbers. Constr Build Mater, 63 (2014), pp. 206-213.

9. KHALOO, A. R., DEHESTANI, M., RAHMATABADI, P. Mechanical properties of concrete containing a high volume of tyre-rubber particles, Waste Management, 28 (2008), pp. 2472-2482.

10. YOUSSF, O., EL GAWADY, M.A., MILLS, J.E., MA, X. An experimental investigation of crumb rubber concrete confined by fibre reinforced polymer tubes. Constr Build Mater, 53 (2014), pp. 522-532. 
11. ANAGNOSTOPOULOS, C.A. Cement-clay grouts modified with acrylic resin or methyl methacrylate ester. Physical and mechanical properties. Constr. Build. Mater., 21 (2) (2007), pp. 252-257.

12. AGGARWAL, L.K., THAPLIYAL, P.C., KARADE, S.R. Properties of polymermodified mortars using epoxy and acrylic emulsions. Constr. Build. Mater., 21 (2) (2007), pp. 379-383.

13. ANAGNOSTOPOULOS, A. C., SAPIDIS, G., PAPASTERGIADIS, E. Fundamental properties of epoxy resin-modified cement grouts, Construction and Building Materials, 125 (2016), pp. 184-195.

14. SHU, X. W., ZHANG, Y. Mechanical Properties of Modified Epoxy/Rubber Concrete, Materials Science Forum, 859 (2016), pp. 39-44.

15. WERKEMA, M. C. C.; AGUIAR, S. Planejamento e Análise de Experimentos: Como identificar as principais variáveis influentes em um processo. Belo Horizonte, Fundação Christiano Ottoni, 1996.

16. MONTGOMERY, D. C. Design and Analysis of Experiments. $5^{\text {th }}$ ed. United States of America, Wiley, 2001.

17. HOlMES, N., BROWNE, A., MONTAGUE, C. Acoustic properties of concrete panels with crumb rubber as a fine aggregate replacement. Constr Build Mater, 73 (2014), pp. 195-204.

18. MARTUSCELLI, C. C., PANZERA, T. H., DIAS, R. F. Mechanical properties of polymer-cementitious composites based on rubber wastes. 14th International Conference of Non-Conventional Materials - IC NOCMAT 2013, João Pessoa, Brazil. 19. PANZERA, T. H., STRECKER, K., ASSIS, M. A. O. Recycling of rubber waste into cementitious composites. $11^{\circ}$ NOCMAT - Non-Conventional Materials and Technologies, 2009, Bath, UK.

20. ASTM D 695 - 02a, Standard Test Method for Compressive Properties of Rigid Plastics, 2002.

21. ASTM D638-03, Standard Test Method for Tensile Properties of Plastics. West Conshohocken, Pennsylvania, 2003.

22. ASTM D 790 - 07. Standard Test Method for Flexural Properties of Unreinforced and Reinforced Plastics and Electrical Insulating Materials, 2007.

23. BS EN ISO 10545-3, Ceramic Tiles - Part 3: Determination of water absorption, apparent porosity, apparent relative density and bulk density, 1997.

24. GANJIAN, E., KHORAMI, M., MAGHSOUDI, A.A. Scrap-tyre-rubber replacement for aggregate and filler in concrete. Constr Build Mater, 23 (2009), pp. 1828-1836.

25. NEVILLE, A. M., Properties of concrete, Harlow, Longman, 1997.

26. ROMUALDO, A. C, DOS SANTOS, D. E, DE CASTRO, L. M. Pneus inservíveis como agregados na composição de concreto para calçadas de borracha. 3rd International Workshop - Advances in Cleaner Production, São Paulo - Brazil, 2011. 27. GESOĞLU, M., GÜNEYISI, E., KHOSHNAW, G., IPEK, S. Abrasion and freezingthawing resistance of pervious concretes containing waste rubbers. Constr Build Mater, 73 (2014), pp. 19-24. 
28. NACIF, G.L., PANZERA, T. H., STRECKER, K., CHRISTOFORO, A. L., PAINE K. Investigations on Cementitious Composites based on Rubber Particle Waste Additions, Materials Research, 16 (2012).

(1) C THOMAS, PHR BORGES, TH PANZERA, A CIMENTADA, I LOMBILLO, Epoxy composites containing CFRP powder wastes, Composites Part B: Engineering 59, 260-268

(2) J NORAMBUENA-CONTRERAS, C THOMAS, R BORINAGA-TREVIÑO, I LOMBILLO, Influence of recycled carbon powder waste addition on the physical and mechanical properties of cement pastes, Materials and Structures 49 (12), 5147-5159

(3) C THOMAS, I LOMBILLO, JA POLANCO, L VILLEGAS, J SETIÉN, MV BIEZMA, Polymeric and cementitious mortars for the reconstruction of natural stone structures exposed to marine environments, Composites Part B: Engineering 41 (8), 663-672 